\title{
Directionally Selective Mnemonic Properties of Neurons in the Lateral Dorsal Nucleus of the Thalamus of Rats
}

\author{
S. J. Y. Mizumori and J. D. Williams \\ Department of Psychology, University of Utah, Salt Lake City, Utah 84112
}

The hippocampal formation has been extensively studied for its special role in visual spatial learning and navigation. To ascertain the nature of the associations made, or computations performed, by hippocampus, it is important to delineate the functional contributions of its afferents. Therefore, single units were recorded in the lateral dorsal nucleus of the thalamus (LDN) as rats performed multiple trials on a radial maze.

Many LDN neurons selectively discharged when an animal's head was aligned along particular directions in space, irrespective of its location in the test room. These directionsensitive cells were localized to the dorsal aspect of the caudal two-thirds of the LDN, the site of innervation by retinal recipient pretectal and intermediate/deep-layer superior colliculus cells (Thompson and Robertson, 1987b). The directional specificity and preference of LDN cells were disrupted if rats were placed on the maze in darkness. If the room light was then turned on, the original preference was restored. If the light was again turned off, directional firing was maintained briefly. Normal directional firing lasted about 2-3 min. After this time, the directional preference (but not specificity) appeared to "rotate" systematically in either the clockwise or counterclockwise direction. The duration of normal directional discharge patterns in darkness could be extended to $\mathbf{3 0} \mathrm{min}$ by varying the behavior of the animal. LDN cells required visual input to initialize reliable directional firing. After the rat viewed the environment, directional specificity was maintained in the absence of visual cues.

Maximal directional firing was achieved only when the rat viewed the entire test room, and not just the scene associated with the directional preference of the cell. Thus, contextual information seems important. Also, a significant correlation was found between directional specificity and errors made on the maze during acquisition of the task. It was concluded that the LDN may pass on to the hippocampal formation directional information that is not merely a reflection of current sensory input. As such, the LDN may serve an important integrative function for limbic spatial learning systems.

[Key words: lateral dorsal thalamus, spatial navigation, directional coding, single-unit activity, tectocortical system]

\footnotetext{
Received Aug. 10, 1992; revised Mar. 15, 1993; accepted Apr. 7, 1993.

This work was supported by NSF Grant BNS 9120784 to S.J.Y.M. We thank James G. Canficld for comments on the manuscript, and Heather Hovde and Karen Burk for assistance with the behavioral testing of animals and data analysis.

Correspondence should be addressed to Dr. Sheri J. Y. Mizumori, Department of Psychology, 502 Social and Behavioral Science Building, University of Utah, Salt Lake City, UT 84112.

Copyright (C) 1993 Society for Neuroscience $0270-6474 / 93 / 134015-14 \$ 05.00 / 0$
}

Different forms of spatially relevant information appear to be processed by distinct brain regions. For instance, the parietal cortex is involved in spatial perceptual processes (such as object localization and feature detection), spatial attention, spatial construction, and mental rotation (e.g., Andersen, 1987; Farah, 1988; Morrow and Ratcliff, 1988). The superior colliculus is thought to integrate visual, auditory, and somatosensory information in such a way that appropriate saccades are made to particular locations in space (Sparks, 1989). The hippocampal formation has been studied extensively for its contribution to learning and memory, often with a special cmphasis on visual spatial navigation (e.g., O'Keefe and Nadel, 1978). A complete understanding of the neurobiological mechanisms by which associative processes within any brain structure guide spatial behavior requires specification of both the nature of the structure's intrinsic integrative processes, and the functional contributions of sensory and motor afferents. With respect to the hippocampal formation, various neural computational theories have been proposed to account for intrahippocampal spatially relevant integration processes (McNaughton and Nadel, 1990; O'Keefe, 1990; Rolls, 1990). However, there is little, if any, empirical data concerning the functional contribution of afferent information to these integrative computations. Therefore, the present study investigated possible functional contributions of one of the major afferent systems to the hippocampal formation.

Computational models of hippocampal function typically incorporate the well-known result that a primary detcrminant of CA1 and CA3 pyramidal cell discharge is the location of an animal in its environment (Ranck, 1973; O'Keefe, 1976; Olton et al., 1978; McNaughton et al., 1983a; Muller et al., 1987). These "place cells" exhibit elevated firing when an animal traverses localized areas of space, referred to as "place fields." Place fields appear to be driven at least in part by visual input. If an animal is carried into a dark room, pyramidal cell discharge is not reliably associated with a particular location in the environment (McNaughton et al., 1989). However, when the animal is first permitted to view the test environment before room lights are turned off, or before visual cues are physically removed (O’Keefe and Speakman, 1987; Quirk et al., 1990), locationspecific firing is maintained for a short period of time. Therefore, although place fields are dependent on visual input, they do not reflect merely the immediate sensory environment. Rather, it is thought that the hippocampus maintains ncural representations of visual spatial aspects of the environment, and these representations facilitate accurate spatial navigation.

Hippocampus proper receives most of its inputs from cells in the superficial layers of the entorhinal cortex (Matthews et al., 1976; Steward and Scoville, 1976; Lee et al., 1977). These entorhinal cells exhibit location-specific firing (Quirk and Ranck, 
1986; Barnes et al., 1990; Mizumori et al., 1992; Quirk et al., 1992) similar to hippocampal place cells in that they are both sensitive to rotation of the visual environment, and they persist when cues are removed. In contrast to hippocampal place fields, however, entorhinal place fields were "topologically transformed" when the animal was placed into environments of different shapes. Hippocampal cells often stop firing altogether under these same test conditions. Thus, spatial representations in entorhinal cortex appear to be less sensitive to subtle environmental changes than hippocampal place cells. Nevertheless, it is evident that place-related representations are constructed in structures directly afferent to hippocampus proper (Quirk et al., 1992). The origin of entorhinal place fields is not clear. However, given that the postsubiculum projects to entorhinal cortex (van Groen and Wyss, 1990b), and that postsubicular cells code visually dependent directional information (Taube et al, 1990a), it is possible that the postsubiculum contributes a portion of the spatially relevant data processed by entorhinal cortex.

Visual afferents arrive in entorhinal cortex and postsubiculum via the geniculostriate and tectocortical systems. In rat, the tectocortical pathway appears to predominate. For example, some $90 \%$ of retinal ganglion cells project to the pretectum/superior colliculus area while only about $20-50 \%$ of retinal ganglion cells project to the dorsal lateral geniculate nucleus (Linden and Perry, 1983; Sefton and Dreher, 1985). Within the superior colliculus, superficial layer (I-III) cells are involved in spatial analysis (Casagrande et al., 1972; Ingle, 1982) much like in the geniculostriate system. In contrast, intermediate/deep layers (IV-VI) of superior colliculus play a special multisensory role in spatially guided behavior (Meredith and Stein, 1985; Dean, 1990). That is, these layers, which maintain integrated visual, auditory, and somatosensory maps (Sparks, 1989), may provide a system by which directional movements of the eyes and head are guided by the current constellation of cues present in an environment, and not by individual stimuli. Berthoz (1990) further postulates that after information passes through the superior colliculus, it enters a "dynamic memory" system that provides for stability of the internal representations of the visual environment despite continually changing retinal input.

The intermediate/deep layers of superior colliculus project to the lateral dorsal nucleus of the thalamus (LDN), which also receives direct input from retinal recipient pretectal nuclei (olivary nucleus, nucleus of the optic tract, and posterior pretectal nucleus; Thompson and Robertson, 1987b). LDN cells that receive these pretectal/superior collicular afferents in turn project directly to a number of cortical structures, notably the hippocampal formation (i.e., the subicular complex and entorhinal cortex), dorsal retrosplenial cortex, area $18 \mathrm{~b}$, and parietal cortex (Vogt and Miller, 1983; Vogt et al., 1986; Thompson and Robertson, 1987a; van Groen and Wyss, 1990a,b, 1992). Retrosplenial cortex transmits (presumably) visual information from areas 17 and 18 to hippocampus. Thus, it would seem that the LDN is not only strategically situated to modulate directly the preprocessed tectocortical visual input to the hippocampal formation, but also may indirectly affect visual afferents derived from the geniculostriate system (Sripanidkulchai and Wyss, 1986; Thompson and Robertson, 1987a,b; van Groen and Wyss, 1990a,b, 1992).

Given the visual sensitivity of spatial representations within the hippocampal formation, together with the finding that the most direct pathway by which visual information arrives in hippocampus is via the retina-superior colliculus-LDN-subicular complex/entorhinal cortex route, we began our examination of the nature of sensory afferents to the hippocampal formation by recording LDN single-unit activity as rats performed a spatial memory task on an eight-arm radial maze.

Portions of this study have been described in abstract form (Mizumori and Williams, 1991).

\section{Materials and Methods}

Animals. Seven male Fischer-344 rats (9-month-old retired breeders) were obtained from Charles River Laboratories. Upon arrival, free access to food and water was permitted for at least 2 weeks. During this time, the animals were handled and weighed. Food was restricted throughout behavioral training such that the animals maintained body weights that were about $80 \%$ of their ad libitum body weights. Behavioral testing occurred between 0730 and $1200 \mathrm{hr}$. Lights were on in the colony room from 0700 to $1900 \mathrm{hr}$.

Behavioral testing apparatus and procedure. Elevated, semi-automated black plastic eight-arm radial mazes (Olton and Samuelson, 1976) were used to test the spatial performance of the rats. Each maze consists of eight alleys, or arms, that radiate from a round central platform. Each arm of the maze is hinged perpendicular to the long axis so that the proximal part of the arm can be raised flush with the central platform, or lowered, to restrict access to the food reward at the arm ends. Additional details of the maze apparatus can be found in Mizumori et al. (1989). Presentation of individual arms was accomplished by remote control. Several objects that could have served as extramaze cues included a table, chair, miscellaneous laboratory equipment, and an experimenter. The primary recording room (room 1) was illuminated with a single $40 \mathrm{~W}$ light bulb located in the southeast corner of the room. A second recording room (room 2) was available for some of the tests described below. Room 2 also contained a table, chair, miscellaneous equipment, and a single light bulb. However, the spatial arrangement of these objects was different from that of room 1 .

Aninals were initially trained according to a standard training procedure. This training protocol was essentially the same as that described previously (Mizumori et al., 1990). Briefly, chocolate milk reward $(0.2$ $\mathrm{ml}$ ) was placed in food cups located at the distal ends of arms. At the beginning of a trial, the rat was placed on the central platform. The optimal strategy for solving the maze (i.e., retrieving all of the food reward) was to enter each arm only once per trial. Reentries into previously visited arms were considered errors. The first four arms sampled per trial (sample phase) were sequentially presented by the experimenter to the rat in random order to minimize its use of a response strategy for solving the maze. The particular sequence of arms varied from trial to trial. When food was retrieved from the first four arms, all eight arms were presented simultaneously and the rat was allowed to complete the trial by selecting those arms not already entered during that trial (memory phase). Rats were initially trained to perform 10 such trials per day (intertrial interval, $2 \mathrm{~min}$ ). The experimenter recorded the number of errors made per trial and the time required to complete each trial. When rats performed 10 trials within $1 \mathrm{hr}$ for 7 consecutive days, free access to food was allowed for the next 2-3 d. Electrodes were then surgically implanted. Postsurgery training proceeded in an identical manner as during the presurgery period except that the rats were required to perform 15 trials per day. When LDN cells were encountered, the specific behavioral testing schedule varied according to the objectives of individual experiments. These procedures are described in more detail below. For all tests, however, "standard training condition" refers to performance on the mazc as describcd above.

Electrode construction and surgical procedure. After the rats achieved criterion performance levels on the radial maze, recording electrodes were stereotaxically implanted under aseptic conditions. The surgical procedure proceeded essentially as described previously (Mizumori et al., 1989). Briefly, rats were first intraperitoneally injected with $30 \mathrm{mg}$ / $\mathrm{kg} \mathrm{Nembutal}(50 \mathrm{mg} / \mathrm{ml})$ followed by supplements of $0.05 \mathrm{ml}$ as necessary. Small burr holes were drilled in the skull. The stereotaxic coordinates for $L D N$ recording were AP $2.3-2.8 \mathrm{~mm}$ posterior to hregma, $1.7 \mathrm{~mm}$ lateral of the midsagittal suture, and 4-5 $\mathrm{mm}$ below the dural surface (Paxinos and Watson, 1986). Two stereotrodes (described below) were implanted per hemisphere. One stereotrode was situated $2.3 \mathrm{~mm}$ posterior to bregma, while the other was placed $2.8 \mathrm{~mm}$ posterior to bregma. These stereotrodes were lowered $1.5 \mathrm{~mm}$ into cortex during 
surgery. Following recovery from surgery, the electrodes were lowered through hippocampus, then the LDN.

Each recording electrode ("stereotrode"; McNaughton et al., 1983b) consisted of two lacquer-coated tungsten wires $(20 \mu \mathrm{m}$ diameter $)$ that were twisted together, dipped in Epoxylite, and then baked. The tips were cut and then gold-plated to give final impedances of $100-200 \mathrm{~K} \Omega$ (tested at $1 \mathrm{kHz}$ ). Individual stereotrodes were threaded through a 30 gauge stainless steel tube that was mounted on a movable microdrive. The microdrive allowed one to advance the electrode toward the target nucleus in roughly $20 \mu \mathrm{m}$ increments. A reference electrode (114- $\mu \mathrm{m}$ diameter Teflon-coated stainless steel wire) was placed into corpus callosum, and a ground lead was soldered to a small jewelers screw secured to the skull. The rat was allowed to recover from surgery for $7 \mathrm{~d}$.

Single-unit and EEG recording. The stereotrode recording technique (McNaughton et al., 1983b) was employed for single-unit recording. This method involves independently recording cellular activity through two adjacent fine electrode wires. Stereotrode recording facilitates unit isolation by making use of the ratios of spike characteristics recorded on two channels ( $\mathrm{x}$ and $\mathrm{y}$ ). Incoming signals were amplified $(5-10 \mathrm{~K})$, filtered at $600 \mathrm{~Hz}$ and $6 \mathrm{kHz}$, and then passed through a window discriminator such that a $1 \mathrm{msec}$ sampling period began when a signal from either channel exceeded a predetermined threshold. The signals were transmitted to a BrainWave Neuroscience Workstation AST 80386based computer system and the entire spike waveform was sampled at a frequency of $32 \mathrm{kHz}$ per channel. The experimenter isolated single units by using an interactive cluster analysis program. The system software processed the signals according to at least eight parameters (four for each recording channel): the maximum and minimum voltages of the waveforms, and the latencies of these values from the onset of the sampling period. Since each analog trace was saved on computer in its entirety, a template matching program was also used to isolate further a single waveform type from others that might occupy the same cluster parameter space. Once the parametric space was defined for each cell, it was subsequently analyzed for its behavioral correlates.

$\mathrm{EEG}$ records were sampled at the beginning of recording sessions. The signal from one wire of the stereotrode pair was amplified 10,000 times, band-pass filtered $(30 \mathrm{~Hz}$ to $0.6 \mathrm{~Hz})$, and then observed on an oscilloscope.

Behavioral monitoring. A headstage composed of five FET (unity gain) preamplifiers and an infrared light-emitting diode (LED) was attached to the connecting socket on the rat's head for all behavioral and recording sessions. The LED was located about $2 \mathrm{~cm}$ directly above the rat's head. The rat's movements about the maze were monitored via an automatic tracking system that sampled and recorded the $x, y$-coordinates of the diode at a frequency of $20 \mathrm{~Hz}$. The time of each position sample was logged along with the time of each spike event. The output of the camera was also transmitted to a video recorder and monitor. One experimenter remained in the maze room while another experimenter monitored the computer, recording, and video equipment located in an adjacent room.

Unit identification and analysis. LDN cellular activity was initially identified relative to hippocampal units. As the electrodes were advanced through hippocampus, a characteristic and reliable pattern of discharge was encountered. For example, about $2 \mathrm{~mm}$ below the dural surface, CA1 theta and complex-spike cells were observed. Stratum granulosum and hilar complex-spike cells were then observed about $700-900 \mu \mathrm{m}$ ventral to CA1. Single-spiking IDN cells were detected some $500 \mu \mathrm{m}$ after exiting the dentate gyrus region. EEG records further distinguished the LDN from the hippocampus. For example, rhythmic modulation $(7-9 \mathrm{~Hz})$ of the EEG was observed during periods of behavioral immobility when recording in the LDN. In contrast, such rhythmicity was observed in hippocampus during periods of active locomotion. Finally, the location of the electrode track was verified with standard histological techniques. That is, $40-\mu \mathrm{m}$-thick frozen coronal sections were stained with cresyl violet and then observed under a microscope.

Given the possible contribution of the LDN to spatial navigation systems, unit discharge was analyzed with respect to the direction of an animal's movement as well as its location on the maze. The direction of movement was determined by monitoring the temporal order of position points. The highly maze-trained animals always traversed the maze arms in the forward direction. Therefore, it was assumed that diode movement inward or outward on maze arms reflected movement by the rat along identifiable trajectories in space. The firing rates as the diode (rat) moved inward and outward on maze arms were used to calculate discharge rates associated with each of eight radial directions.
The average firing rate as the rat moved outward on one arm and inward on the opposite arm represented the rate as the rat moved in one direction. Thus, eight rates were used in calculating directional specificity. Dircctional spccificity was quantified by calculating a directional index (DI) score. The DI was determined by dividing the highest rate by the mean of the remaining seven rates. A cell was considered directionally specific if the DI score was 3.0 or greater. Thus, firing in the preferred direction was at least three times greater than firing in other directions. The preferred direction of a cell corresponded to the direction associated with the highest rate.

To illustrate graphically the location and directional properties of LDN cells, "spot-rate" plots were generated as follows (see Figs. 2, 710 , for examples). The mean firing rate of the cell was determined while the rat remained within a 5-pixel radius $(7.5 \mathrm{~cm})$ of the first position sampled. When the diode moved outside this radius, the new position point served as the next integration center, and the firing rate that corresponded to that location was calculated. The graphic output consisted of dots (indicating occupied positions on the maze) and circles whose radii were linearly proportional to the local firing rate of the cell. The vectors radiating from the center of the circles revealed the direction of diode movement when the rat occupied that particular location on the maze.

Perievent histograms were also used to evaluate LDN unit activity. To create the histograms, the position data could be replayed on a monitor in the same temporal and spatial sequence as that observed during the recording session. Event markers were entered into the data stream at points that corresponded to behaviors of interest, such as when the rat reached the ends of maze arms (see Fig. 2). Then, the firing rate $2.5 \mathrm{sec}$ before and after the behavior event was plotted in histogram form.

\section{Results}

An average of 4 weeks was required before animals attained criterion performance prior to surgery. After 1 week of postsurgical training, animals daily performed 15 trials within an hour. At the time of recording LDN cells, animals were performing the maze at asymptote levels, making an average of less than one error per trial under standard training conditions. Typically, each trial was performed in 1-2 min.

Seventy-five cells were recorded from seven rats. Based on histological reconstructions and electrode depth measurements, 50 of these were identified as LDN neurons, and 25 units were categorized as lateral posterior nucleus (LPN) cells. For comparison, LPN data were included in some of the present analyses. According to the rostral-caudal distinction provided by Thompson and Robertson (1987a,b) and van Groen and Wyss (1992), 43 cells were located in the middle to caudal portion of LDN and 7 were found in the rostral tip of the LDN. Rostral and caudal LDN neurons did not differ in terms of mean $( \pm \mathrm{SE})$ spike amplitude $(141.3 \pm 28.1 \mu \mathrm{V}$ and $147.5 \pm 13.5 \mu \mathrm{V}$, respectively). Also, the average firing rates during maze performance were similar for rostral and caudal LDN cells $(9.81 \pm$ $3.21 \mathrm{~Hz}$ and $8.95 \pm 1.62 \mathrm{~Hz}$, respectively), although the current firing rate often times varied (range, 1-35 Hz) with changes in the behavioral condition of the animal (described in detail below).

Anatomical evidence suggests a functional distinction between the dorsal and ventral aspects of caudal LDN (Thompson and Robertson, 1987a,b; van Groen and Wyss, 1992). For example, dorsal LDN receives more extensive input from deep layers and visual areas of the pretectum and superior colliculus. Therefore, the behavioral properties of caudal-dorsal $(n=29)$ and caudal-ventral $(n=14)$ LDN units were compared.

LDN recordings were usually very stable across days. In fact, one cell was recorded for 6 weeks. On a few occasions, multiple LDN cells were recorded within the same session. EEG records taken during periods of awake immobility and locomotion were 

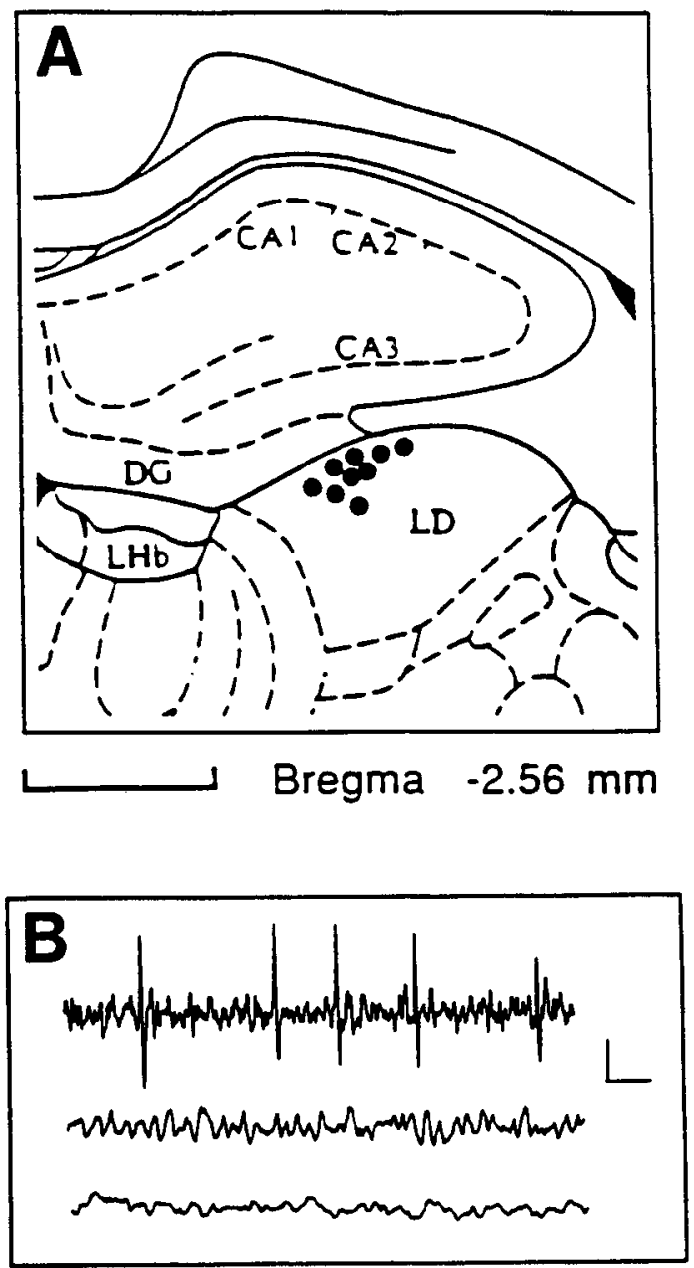

Figure 1. A, Schematic representation of a coronal section through a rat brain indicating the locations at which direction-sensitive cells were recorded in the LDN $(L D)$ (solid circles). Each circle may correspond to the recording site of more than one directional cell. Note the cluster of circles in the dorsal aspect of the LDN. Units were recorded in more rostral, ventral, and posterior sectors of the LDN, but directional cells were not observed in these areas. From Paxinos and Watson (1986). Scale bar, $1 \mathrm{~mm}$. $B$, Examples of analog traces of LDN electrical activity. Top trace, LDN directional cells discharged at high frequencies when the animal faced the preferred direction of the cell. Calibration: $70 \mu \mathrm{V}$, $2 \mathrm{msec}$. Middle trace, EEG varied as a function of behavior of the animal. During periods of relative immobility, synchronous patterns $(7-9 \mathrm{~Hz})$ were observed. Calibration: $50 \mu \mathrm{V}, 8 \mathrm{msec}$. Bottom trace, During periods of active locomotion, comparatively flat and desynchronous EEGs were recorded. Calibration: $50 \mu \mathrm{V}, 8 \mathrm{msec}$.

consistent with those described for other areas of thalamus (Fig. $1 B$; Steriade and Llinas, 1988). That is, in contrast to that found for the hippocampus (Vanderwolf, 1969), 7-9 Hz modulation was observed during relatively inactive periods, and desynchronized records were observed during locomotion. This pattern was observed in all subregions of the LDN.

\section{Head direction firing by caudal-dorsal LDN cells}

The most striking behavioral correlate of many LDN cells was that their discharge rate increased dramatically when an animal's head was aligned with particular directions in horizontal space, irrespective of the precise spatial location of the animal in its environment (Fig. 2). According to our criteria (described above), $30.0 \%$ of all LDN cells were direction sensitive. Examination of the distribution of directional cells revealed that all directional cells were recorded within the dorsal sector of caudal LDN. Thus, 51.7\% (15 of 29) of dorsal LDN cells responded to the direction in which an animal faced (see Fig. 1), while none of the ventral-caudal or rostral LDN cells showed directional firing. This distribution of directional cells is consistent with the finding that visual afferents arrive in the dorsalcaudal LDN (Thompson and Robertson, 1987a,b), and not the rostral or ventral-caudal arcas. Also, ncurons recorded in the adjacent thalamic structure, the LPN, did not show directional firing patterns (Fig. 3).

To determine whether the directional preference of cells was related to the absolute direction an animal faced rather than spatial location or retinal input per se, animals were held in the experimenter's hand and then "pointed" in one of eight directions (north, northeast, east, southeast, south, southwest, west, and northwest). The rat was deliberately moved to different locations in the test room while recording cellular activity associated with a particular direction. The order of direction tested was randomly determined. Each direction was tested at least five times. The animal remained facing a particular direction for $10 \mathrm{sec}$ before being passively moved to face a different direction. The firing rates during the $10 \mathrm{sec}$ nonmovement periods were compared across the eight directions. After the passive movement tcsts, animals performed maze trials under standard training conditions.

A comparison of the data in Figures 2 and 4 illustrates that the directional selectivity of cells was the same whether the rat was hand-held or performed on the maze. This result was observed for all (15 of 15) directional cells tested, and was true whether or not the animal was allowed to traverse the maze before the passive movement tests. Also, the same directional preference of the cell was observed whether or not the animal was held above the maze or held in a different part of the test room. Thus, the most clear predictor of cell discharge was the direction that the animal was facing. Therefore, we refer to these cells as head direction cells (Ranck, 1984).

The directional preference (e.g., north, northeast, south, etc.) varied between cells. However, for a given cell tested under standard training conditions, the preference remained constant across many recording days. There did not secm to be a bias for directional representation in the LDN: cells were recorded that preferentially fired in each of the eight radial directions tested (Fig. 5). Also, all cells showed clear preferences for only one of the eight directions (Fig. 6). Although multiple LDN cells were recorded in a few sessions, in only one session did we record two clearly directional cells. These two cells had directional preferences to the southeast and southwest. Unfortunately, we were able to hold onto the pair of cells for only a few days. The results of tests conducted on these cells are described below.

\section{Visual dependence of directional discharge}

Based on the known neuroanatomical connections of the LDN, it was hypothesized that the directional firing of LDN cells would change in response to alterations in the visual environment. The visual sensitivity of LDN correlates was tested in three ways. In the first test, the directional firing was recorded as animals performed the first 5 of 15 maze trials under standard training conditions (room 1). Following completion of the fifth trial, the animal was quickly carried to a novel room 2 where similar visual cues were available, although arranged differently. The rat was immediately connected to the recording equipment, 


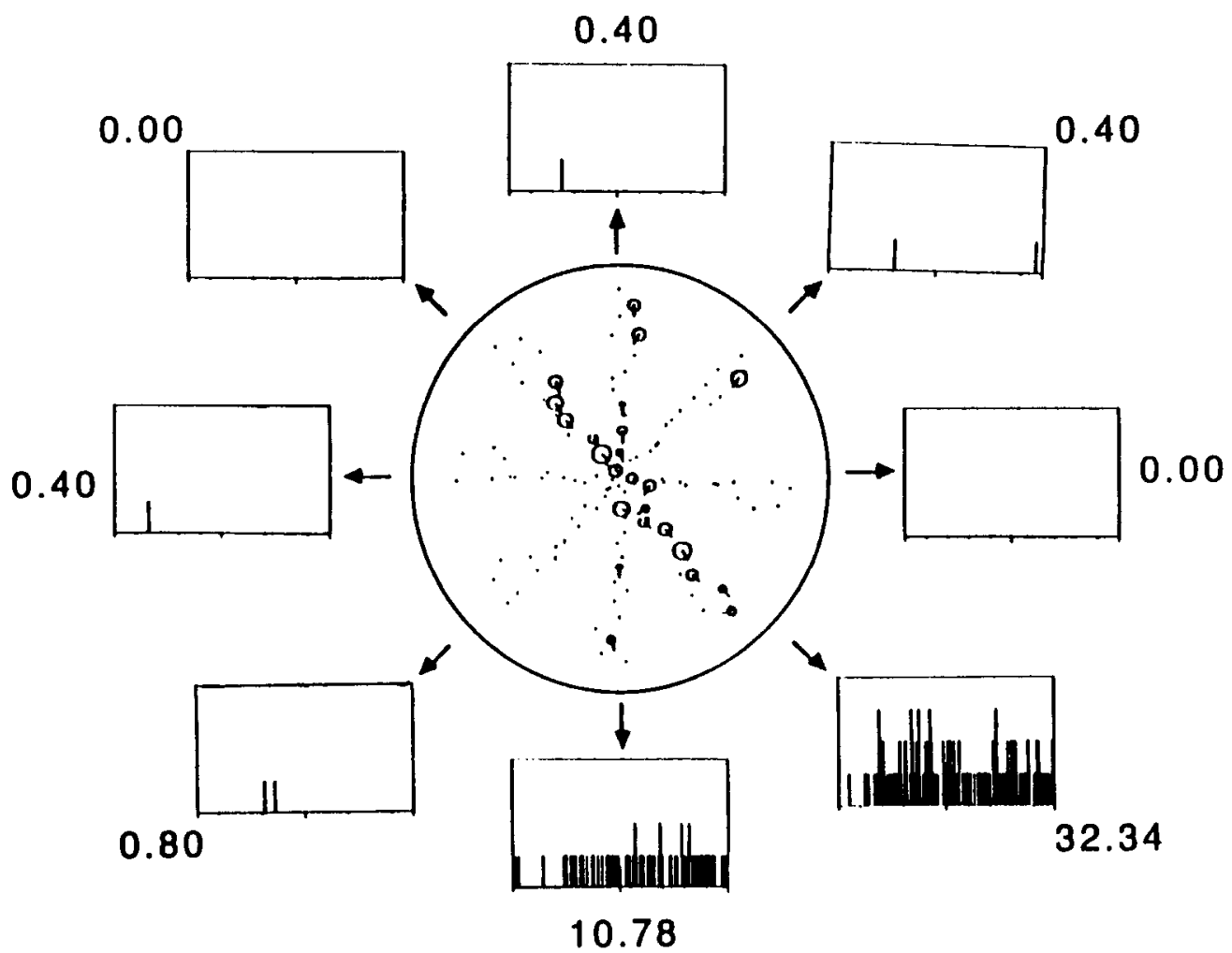

Figure 2. Illustration of directionsensitive discharge by cells in the LDN. Unit activity was monitored as animals performed a radial maze task. The $d i$ agram within the large central circle demonstrates the spatial distribution of unit discharge. Dots correspond to positions occupied by the rat. The radius of the small circles is proportional to the local firing rate of the cell. Vectors radiating from the center of these circles indicate the direction of diode movement. For this and all subsequent spatial distribution figures, north is toward the top. This cell preferentially fired when the rat moved in the southeast direction on the maze. Maximum rate per circle, $107.0 \mathrm{~Hz}$. Arrows point to event histograms that illustrate the firing rate of the cell as the animal faced the direction indicated by the arrow. The origin of the histogram corresponds to the time an animal arrives at the arm ends. Individual histograms show the mean rate $2.5 \mathrm{sec}$ before and after the origin, which corresponds to the time when an animal moves outward on maze arms and when it remains relatively still at the arm end as it consumes the reward. The mean rate $(\mathrm{Hz})$ per direction that the animal faced is indicated by the numbers adjacent to the histograms. Histogram analyses verified that the cell preferentially fired when the animal faced southeast. Bin width is $10 \mathrm{msec}$. and maze trials began. The intertrial interval between trials 5 (room 1) and 6 (room 2) was $2 \mathrm{~min}$. The rat performed trials 6-10 in room 2 . Then, trials $11-15$ were performed in room 1 .

Directional firing was observed in both rooms 1 and $2(n=$ 3 cells, 3 rats; DI $=11.12 \pm 4.38$ and $7.17 \pm 2.17$, respectively). However, the absolute direction preferred by the cells differed between rooms. As an example, the cell presented in Figure 7 preferentially fired when the animal faced west in room 1. In roum 2, the directional preference of the same cell was to the east. Upon returning to room 1 (trials 11-15), the directional preference was once again west. Such a change in the absolute direction preferred by the cell indicates that there is little (if any) geomagnetic contribution to LDN directional firing. Rather, since a similar visual cue (a blank white wall) was present on the west side of the maze in room 1 and the east side of the maze in room 2 , the directional preference exhibited may be determined by visual cues.

The influence of the visual system was tested on two simultaneously recorded directional cells by observing the effects of rotating the single light source in the maze room. When the light was shifted $180^{\circ}$, both units not only maintained their original directional preference, but also began to fire as the rat moved along a trajectory that was $45^{\circ}$ to the left of the original preference. When the light was returned to its original location in the room, the original high degree of specificity was restored for both cells. Thus, changes in the visual environment resulted in similar effects for both cells.

In a third test of visual influences, we examined whether visual input was required for directional firing by LDN cells. An animal was first carried into room 1 in darkness, connected to the recording headstage, and then placed on the central platform of the maze. Importantly, during this time, steps were taken to ensure that the animal did not have access to visual input. For example, the rat was carried through two dark rooms before entering the dark maze room. While the rat was in the maze room, all door jams were covered and lights in the adjacent rooms were turned off. Since the experimenter was unable to see the rat on the maze, a second experimenter in the adjacent room monitored the rat's behavior by viewing the video mon-

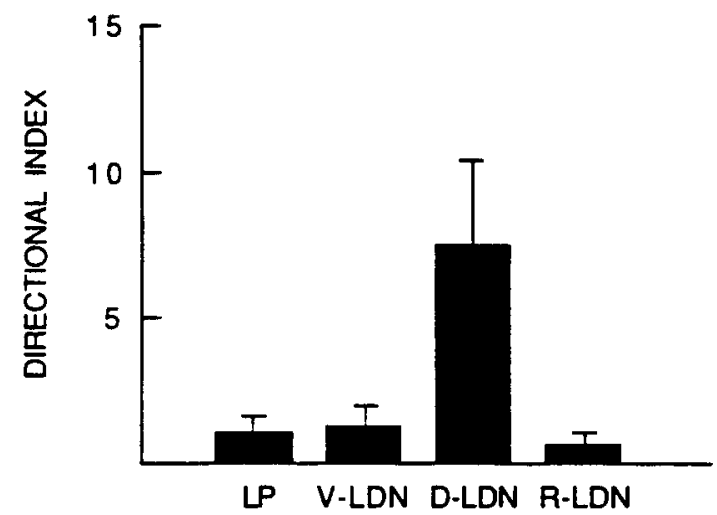

Figure 3. Comparison of DI values obtained for cells recorded in $L P$ (lateral posterior nucleus of the thalamus), $V-L D N$ (ventral portion of caudal LDN), $D-L D N$ (dorsal section of caudal LDN), and the $R-L D N$ (rostral tip of the LDN). The DI was used to quantify the directional specificity of cell discharge (see Materials and Methods for further explanation). A larger index corresponds to more selective firing. Regional specificity of directional firing was indicated by the finding that cells recorded in $D-L D N$ were significantly more directionally selective than cells recorded in $L P$ or other $L D N$ regions. 
Figure 4. Voluntary movement is not necessary for the demonstration of directionally selective firing. The experimenter held the rat in his/her hand and then pointed the rat in different directions in space. The histograms presented demonstrate the firing rates as the animal faced either the NW, NE, $\mathrm{SW}$, or SE directions. The origin of each histogram corresponds to a point in time 3-5 sec after the rat faced a particular direction. Thus, for the duration of the histogram, the animal continually faced the direction indicated. This cell was essentially silent except for when the animal faced SE. This directional preference corresponded to the preference demonstrated by the same cell during subsequent maze trials.
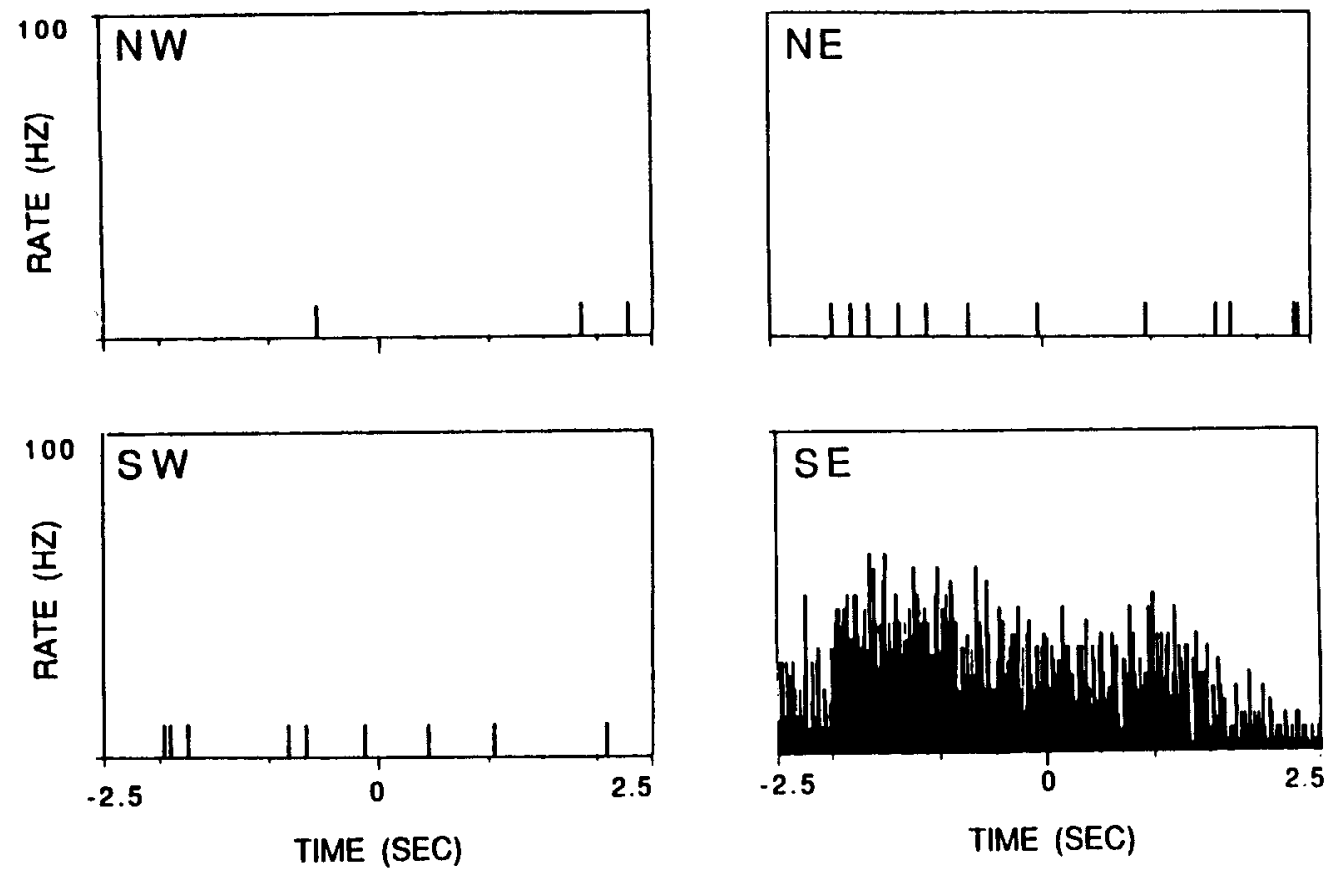

itor. (The infrared signal remains visible to the video camera whether the lights are on or off.) Since rats probably do not detect infrared illumination, we are confident that the rat was deprived of most, if not all, visual input during dark test periods.

The rat performed the first 5 of 20 maze trials in darkness (dark start condition). Lights were also off during the intertrial intervals. After completion of the fifth trial, the room light was turned on and the rat performed trials 6-10 under standard training conditions. Trials 11-15 were then performed in darkness, although the light was on during the intertrial intervals (dark trials condition). Finally, trials 16-20 were performed under standard training conditions.

When compared to performance during light trials (mean \pm $\mathrm{SE}=0.08 \pm 0.02$ errors), the rats made significantly more errors during both dark start $(0.87+0.25)$ and dark trials $(0.75 \pm$ 0.24 ) periods $(p<0.01)$. All LDN directional cells $(15$ of 15 cells, 7 rats), regardless of their initial preferred direction, showed the following pattern of response during different phases of this dark start-dark trials test. During the dark start period, cells fired as the animal moved in many directions in space (e.g., Fig.

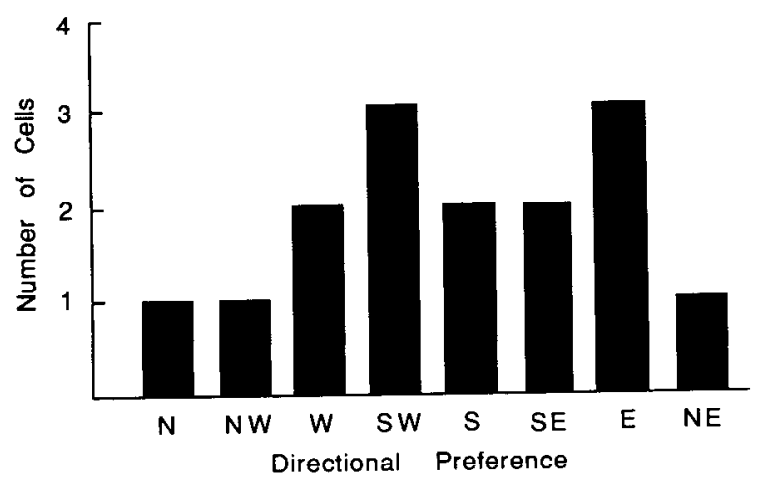

Figure 5. Frequency distribution of the number of cells that exhibited directional preferences in each of the eight directions tested. There was no statistically significant bias for representation of a particular direction.
$8 A$ ). The mean DI was $3.18 \pm 0.43$. The directional specificity became more clear during performance of standard training trials 6-10 (e.g., Fig. $8 B$; DI $=7.78 \pm 1.19$ ). The DI scores did not change significantly during subsequent dark trials 11-15 (e.g., Fig. $8 C$; DI $=6.11 \pm 1.54$ ) or standard training trials $16-$ 20 (e.g., Fig. $8 D$; DI $=8.15 \pm 1.22$ ). Thus, visual information was required to establish LDN directional firing. However, once the animal viewed the room, the directional discharge was maintained in the absence of visual cues. Since visual input was required each day, the directional representation must last less than $24 \mathrm{hr}$.

To evaluate the required duration of exposure to the visual environment for the cstablishment of directional firing, animals $(n=6)$ were subjected to the following test. Rats first performed trials $1-5$ under the dark start condition. Trials 6-10 were also

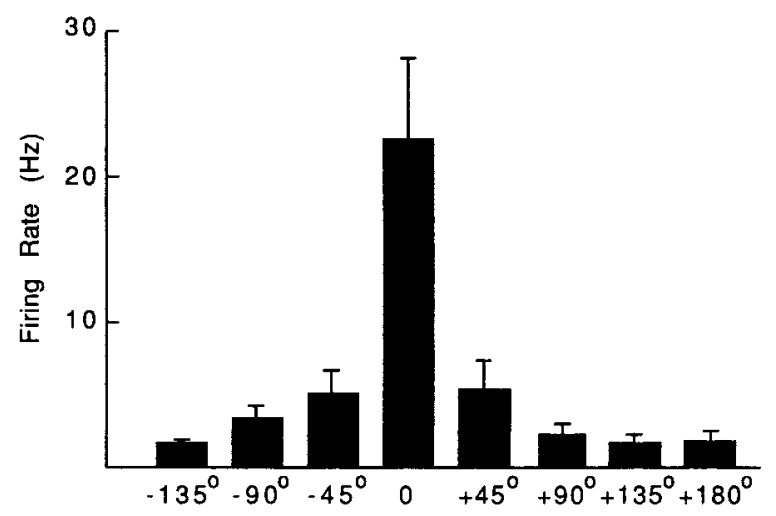

Figure 6. The corresponding mean firing rate $( \pm \mathrm{SE})$ for each of eight directions that an animal faced. All 15 LDN directional cells tested were included in this analysis. The firing rate associated with the preferred direction of each cell was designated the reference direction (0). The rates of cells as animals faced successive $45^{\circ}$ increments to the right $\left(+45^{\circ},+90^{\circ},+135^{\circ},+180^{\circ}\right)$ or left $\left(-45^{\circ},-90^{\circ},-135^{\circ}\right)$ of the preferred direction are also shown. The selectivity of these cells clearly favored only one of the eight directions. 


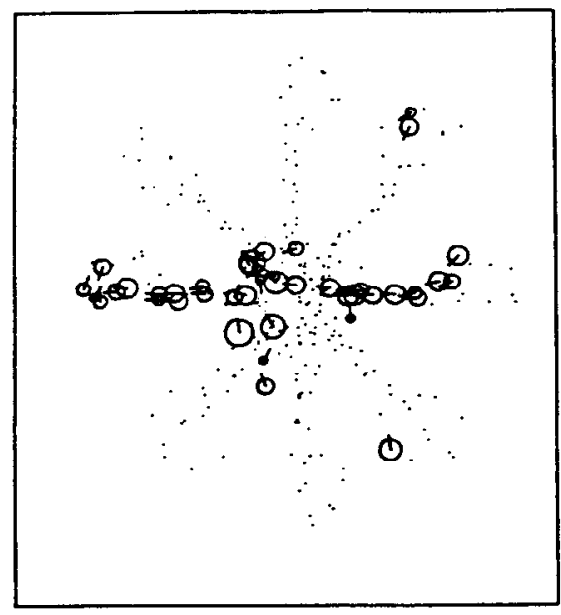

ROOM 1

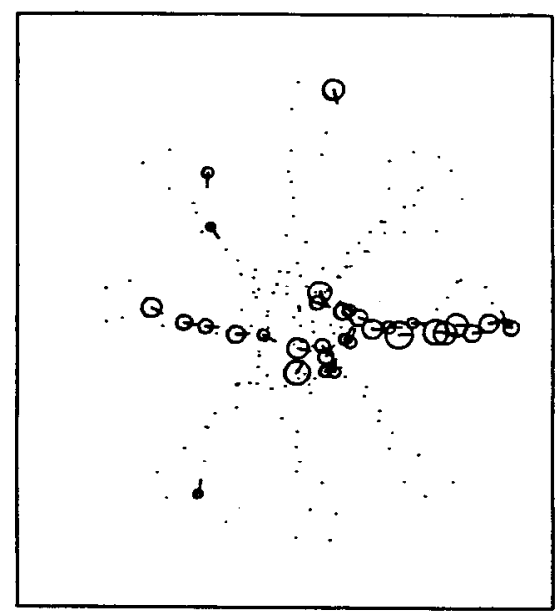

ROOM 2
Figure 7. Local firing rate maps indicating that directional preference of one LDN neuron varied as a function of the room in which an animal was tested. Since the directional preference was different for the two rooms, geomagnetic influences can be ruled out. Rather, this finding suggests extramaze visual stimuli may contribute to directional firing. Maximum rate per circle $=71.25 \mathrm{~Hz}$. performed in darkness. However, immediately prior to the onset of each dark trial $(6-10)$, the room light was turned on for either $2,10,30$, or $60 \mathrm{sec}$. For a given day, only one time period was tested. Thus, it took $4 \mathrm{~d}$ to complete this analysis. Trials 11-15 were always performed under standard training conditions. When compared to performance during standard training trials, all directional cells tested ( $n=13$ ) showed significantly reduced DI scores during the dark start trials $1-5(\mathrm{DI}=3.47 \pm 0.45)$. The directional specificity improved during dark trials 6-10 when the animal was exposed to 2 or $10 \mathrm{sec}$ of light prior to each trial $(\mathrm{DI}=5.15 \pm 1.32$ ). However, in all cases, the preferred direction of the cell was different from that obscrved during standard training trials. Behaviorally, animals made an average of 0.35 \pm 0.13 errors per trial.

When the rat was exposed to 30 or $60 \mathrm{sec}$ of light before each dark trial 6-10, directional specificity appeared similar to that
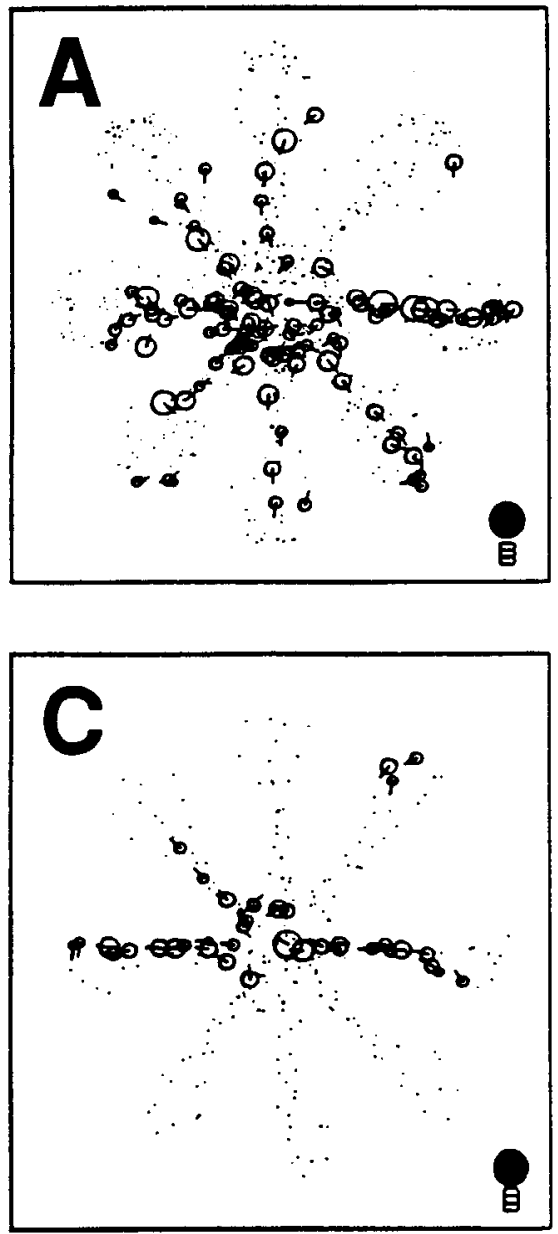
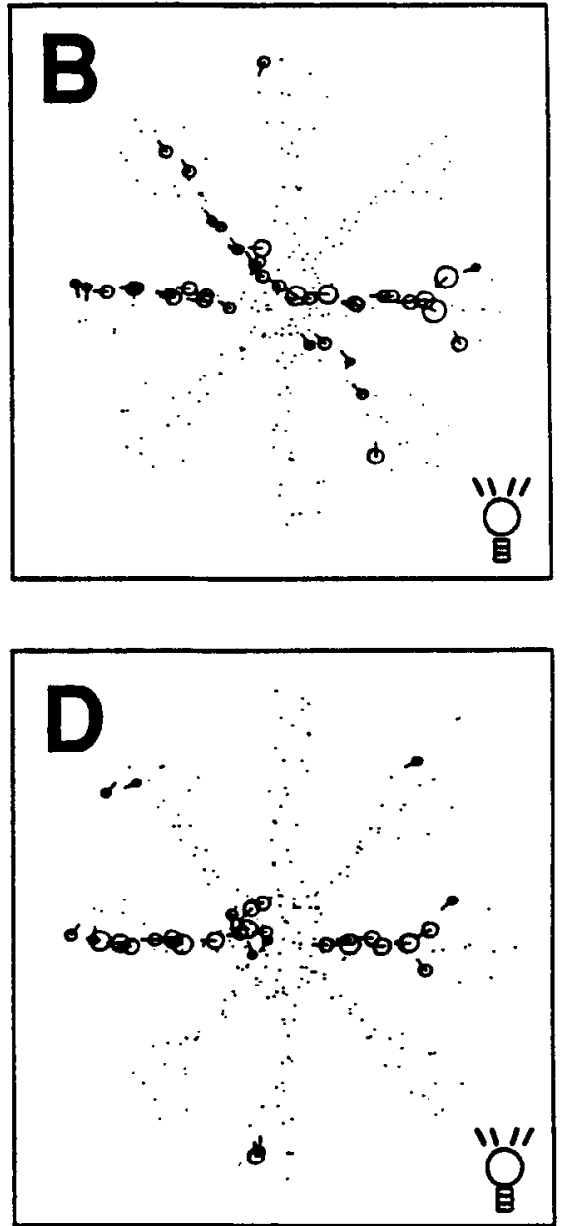

Figure 8. Examples of the spatial distribution of unit firing as the animal performs the maze under four conditions. A dark light bulb in the bottom right corner of each panel indicates that maze trials were performed in darkness. Open light bulb icons indicate that the room light was on during maze trials. $A$, A rat initially performed five maze trials without first viewing the room. This cell fired as the animal moved in many directions. $B$, Two minutes after the lights were turned on, the rat performed trials 6-10. The directional specificity was enhanced, and the cell preferentially fired as the animal moved in a westward direction. $C$, Trials $11-$ 15 were performed in darkness, while the $2 \mathrm{~min}$ intertrial interval was lit. This cell maintained a westward preference. $D$. The final trials $16-20$ were performed with the light on. A westward preference was still clear. This pattern of results demonstrates that the LDN directional representations require visual input to become established each day. However, once the animal views the room, the directional firing is maintained in the absence of visual cues. Maximum rate per circle $=88.21 \mathrm{~Hz}$. 
Figure 9. Illustration of the duration of light exposure required before LDN directional firing is established in a maze-trained rat. Dark and open light bulb icons indicate whether light was available during the intertrial interval before dark trials, or during the trial itself. $A$, The rat performed the first five maze trials in darkness. This cell preferentially fired when the animal moved in several directions. $B$, Either 2 or 10 sec of light preceded maze trials 6-10, which were performed in darkness. In both cases, the firing appeared to become more specific, although the directional preference was not the one subscquently exhibited during maze trials performed with the light on $(D)$. On other test days, the same cell was tested when 30 or 60 sec of light preceded dark trials 6-10 $(C)$. Given these exposure periods, this cell demonstrated the same directional preference and specificity shown during trials 11-15 that were performed with the light on. These results demonstrate that brief $(2-10 \mathrm{sec})$ exposure to even a familiar environment is not sufficient to set up the original directional representation. Rather, more time may be required, perhaps so that an animal can view the environment in its entirety. Maximum rate per circle $=93.7 \mathrm{~Hz}$.
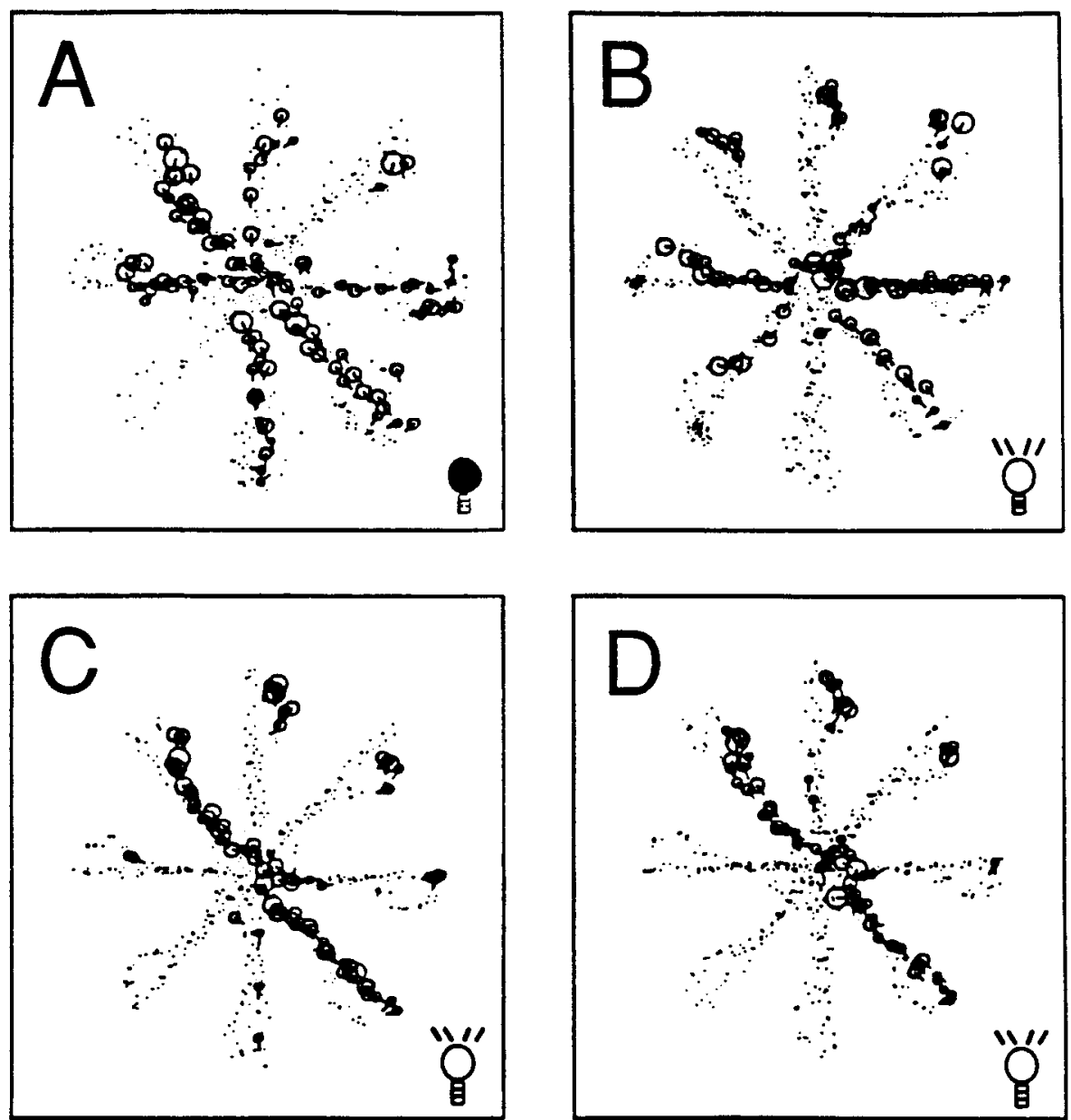

observed during standard trials $11-15[\mathrm{DI}=6.17 \pm 1.23$ (trials $6-10$ ) and $7.62 \pm 1.49$ (trials $11-15$ )]. However, the original directional preference was observed in only $47 \%$ of the tests following $30 \mathrm{sec}$ light exposures. In contrast, all cells tested following $60 \mathrm{sec}$ light exposure showed not only high direction specificity scores but also the same directional preference as that observed when the same cell was tested under standard light conditions. When rats were exposed to $30 \mathrm{sec}$ of light, $0.73 \pm$ 0.29 errors were made per trial. This was significantly more than the $0.06 \pm 0.03$ error made following $60 \mathrm{sec}$ light exposures $(p$ $<0.01)$. Figure 9 provides an example of the effects of exposure to different durations of the visual environment. The LDN behavioral correlate appears to require about $60 \mathrm{sec}$ of exposure to a lit environment before normal directional specificity and preferences are observed.

As indicated above, the directional firing appeared to last for less than $24 \mathrm{hr}$. To elucidate the decay function of the directional representation, animals $(n=6)$ first performed trials $1-5$ under standard training conditions. The room light was then turned off $15,30,60$, or $120 \mathrm{sec}$ before the onset of each of trials 610. Trials 11-15 were performed under standard training conditions. Figure 10 demonstrates the type of change in directional firing observed for all directional cells tested $(n=13)$ as rats performed trials 6-10 following $15-60 \mathrm{sec}$ of darkness. During the first five trials (Fig. 10A), this cell preferentially fired when the rat moved in a northeast direction on the maze $(\mathrm{DI}=18.01)$. The northeast specificity and preference were still observed dur- ing the first dark trial $(\mathrm{DI}=17.62$; Fig. $10 B)$. In subsequent trials, directional specificity was reduced slightly although it remained high (mean DI $=12.32 \pm 1.44$ ). The directional preference, on the other hand, appeared to shift clockwise in roughly $45^{\circ}$ increments across successive dark trials (Fig. $10 C-E$ ). Upon performance of standard trials $11-15$ (Fig. $10 F$ ), the original northeast preference was observed $(\mathrm{DI}=18.41$ ).

The directional preference exhibited apparent clockwise or counterclockwise "rotation" during (dark) trials 6-10. A given cell, however, did not always maintain the same direction of "rotation" during the dark trials. The rotational direction was occasionally observed to shift after two, three, or four dark trials. On test days in which $120 \mathrm{sec}$ of darkness preceded trials 6-10, the directional preferences were observed to change as early as trial 6. Together, these findings indicate that under the behavioral conditions of this test, the directional representation can be maintained in the absence of visual cues for about 2-3 $\mathrm{min}$.

It is possible that the rate of decay of directional information is a function of the extent to which nonvisual cues can provide directional information. To test this, animals were restricted to either the rectangular end of one maze arm or the round central platform in darkness after performing five maze trials under standard training conditions. The animal was free to move about the restricted space during the dark period. To ensure that the animals continued to move about, the experimenter placed a drop of chocolate milk at different places on the maze arm or center platform every few minutes for the duration of the 30 

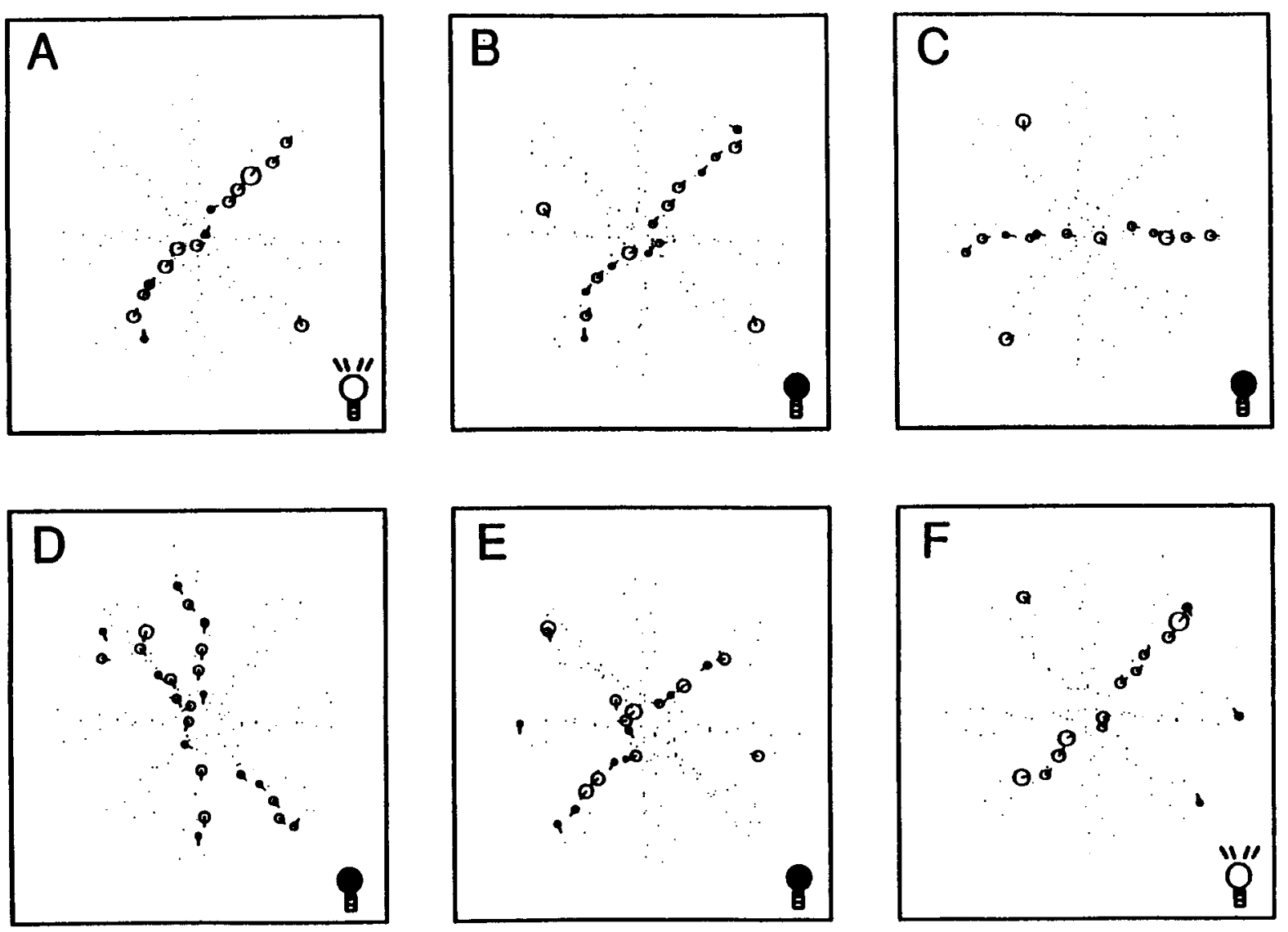

Figure 10. The duration of directional firing by LDN cells. Figure 8 revealed that directional representations do not last 24 hr. In this experiment, animals first performed trials $1-5$ under standard training conditions $(A)$. This cell preferentially fired in the northeast direction. The light was turned off for $30 \mathrm{sec}$ and then the rat performed trial 6 in darkness. $B$ shows that the original directional preference was retained. For the remainder of trials 7-10, lights were off during both the trial itself and the intertrial interval. It can be seen that the preferred direction of the cell changed, giving the appearance of rotating in the clockwise direction, during trials $7-9(C-E)$. Trials $11-15$ were performed under standard training conditions, and the original directional preference was restored $(F)$. Since it took the animal $1.5 \mathrm{~min}$ to solve trial 6 , it is estimated that this representation lasted at least $2 \mathrm{~min}$ in darkness. Maximum rate per circle $=58.8 \mathrm{~Hz}$.

min test period. A second experimenter monitored movement of the diode on the headstage (from the adjacent room) and verified that the animal was indeed moving about throughout the recording period.

The firing rates as the rat faced the preferred and nonpreferred directions were determined with off-line analysis routines. It was found that the DI and preference were unchanged for the entire $30 \mathrm{~min}$ recording session ( $n=5$ cells from 4 rats) if the rat remained on the arm end $(p>0.10)$. If, however, the rat remained on the central platform, the directional preference of the same cells lasted about $2 \mathrm{~min}$ before rotation of the directional preference was observed. Therefore, it appcars that the duration of the directional representation is not merely a function of the passage of time. Rather, the availability of nonvisual cues may contribute to direction preferences by LDN cells when an animal is in a dark environment.

\section{Mnemonic properties of LDN discharge}

The results of the dark start-dark trials test (described above) revealed that directional information can be maintained in the LDN for short periods of time in the absence of visual cues. This finding suggests that the LDN may be part of a system that retains information over time. Possible mnemonic properties of these cells were tested according to one of two test procedures - the context test and the acquisition test.
The context test involved first carrying the rat into the maze room in darkness, connecting it to the recording equipment, and then placing it on the end of a maze arm such that it faced outward. The maze arm selected was one that allowed the animal to face the cell's preferred direction. An experimenter placed a drop of chocolate milk at the arm end about once every 30 sec. After 5 min had passed, the room light was turned on. The experimenter continued to feed the rat chocolate milk, and the rat continued to face the preferred direction of the cell. After a second $5 \mathrm{~min}$ period had lapsed, the experimenter allowed the rat to make one $360^{\circ}$ turn and then fed the rat (facing outward) for another $5 \mathrm{~min}$. Finally, the rat was allowed to make a $180^{\circ}$ turn to face the nonpreferred direction of the cell, where it remained for the final $5 \mathrm{~min}$. The mean firing rates were compared across successive $5 \mathrm{~min}$ epochs.

The four cells tested (from three rats) showed the same pattern of response during the context test. Data presented in Figure 11 illustrate that these cells exhibited relatively low firing rates during the first 5 min dark period (mean rate $=4.5 \mathrm{~Hz}$; Fig. $11 \mathrm{~A}$ ). When the light was turned on (before the animal made the $360^{\circ}$ turn), the rate increased to $7.5 \mathrm{~Hz}$ (Fig. $11 \mathrm{~B}$ ). After the $360^{\circ}$ turn, the firing rate approximated that observed when the rat traversed the maze in the preferred direction during previous test sessions $(28 \mathrm{~Hz})$. Verification that this increase in rate was directionally specific was obtained by comparing Figure 11, $C$ 
Figure 11. Retinal input is insufficient to elicit maximal discharge by directional cells. To test whether merely viewing the scene was associated with the preferred direction of the cell, the rat was carried into the test room in darkness and then placed on the arm end facing the preferred direction of the cell. This cell fired at a low rate $(A), B$, Five minutes later, the room light was turned on and the cell increased firing. $C$, After another $5 \mathrm{~min}$, the animal was allowed to turn about to view the entire maze room. After it turned, the cell now increased its firing by four times when the rat faced the preferred dircetion of the cell. Evidence that the firing was directionally selective is presented in $D$, which shows the relatively low rates of firing as the rat faced the nonpreferred direction. The origin of each histogram corresponds to a point in time 3-5 sec after the rat faced a particular direction. For the duration of each histogram, the rat continued to face one direction in space.
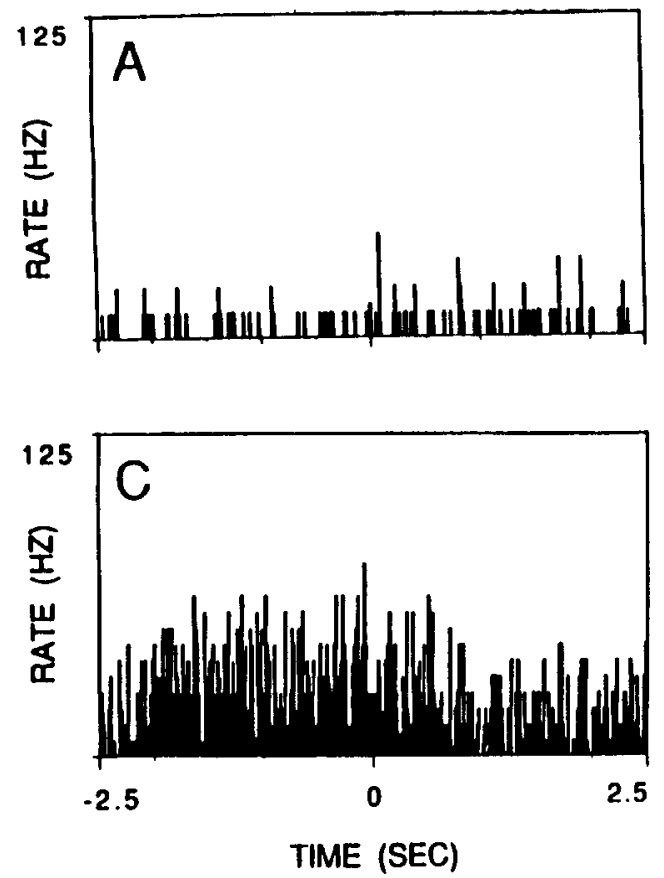
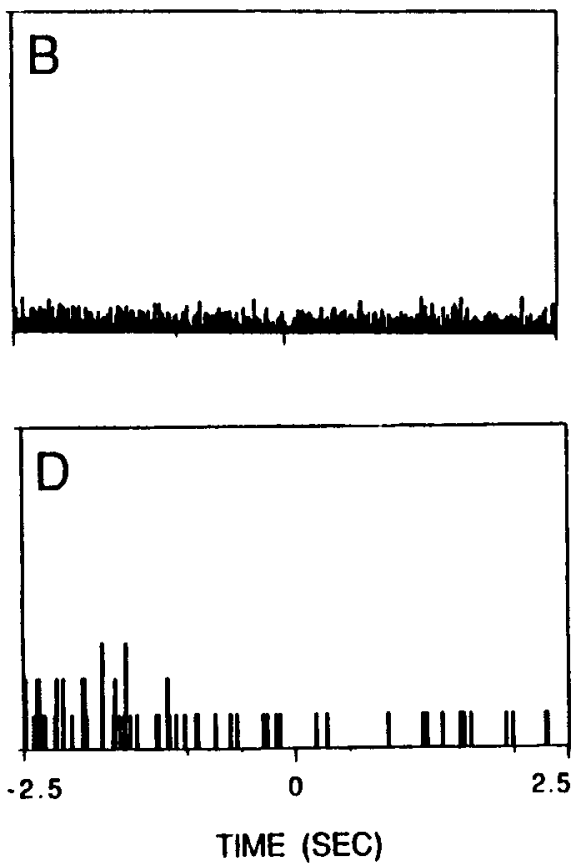

and $D$ : a lower firing rate was observed as the rat faced the nonpreferred direction (Fig. $11 D$ ). The differential firing across successive 5 min epochs cannot be explained readily in terms of the animal's behavior since that was relatively constant across the test periods. Also, within each 5 min period, the rat engaged in multiple behaviors such as drinking milk, sitting still facing outward, or looking upward. It appears that merely viewing the visual scene associated with the preferred dircetion was not sufficient to elicit maximal discharge. Rather, such firing was observed only after the animal viewed additional portions of the room.

The second test of a potential mnemonic function for LDN cells was conducted on two cells recorded from different rats. Naive animals were implanted with recording electrodes. Animals were carried into the computer room where the electrodes

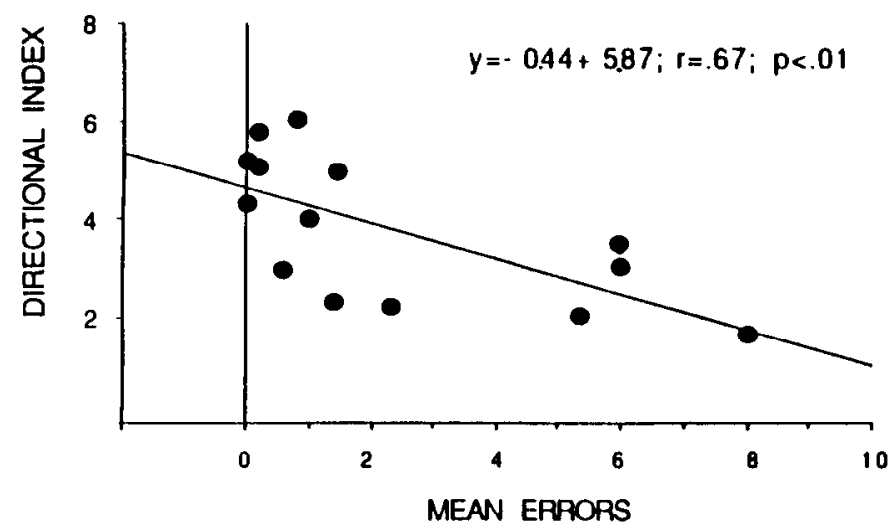

Figure 12. Example of a significant correlation between directional specificity and the number of errors made by a rat during acquisition of the task. Naive animals were implanted with recording electrodes. When LDN neurons were encountered, the rat began maze training. These data show that days when the animal committed many errors are associated with relatively low DI scores. Conversely, days in which the animal performed well are associated with relatively high DI scores. were lowered to the LDN. Importantly, the rat had not been exposed to the maze, maze room, food restriction, or chocolate milk until after a stable LDN cell was found. When a cell was encountered, the rat was allowed to explore the maze for the first time (day 1). Food was then restricted and the rat began maze training on day 2. The number of errors made across training days was correlated with the DI value for those same days. A successful experiment occurred only if the cell was held for the duration of the training period ( 2 weeks). A cell was considered to be the same as the previous day's cell if the spike sort analysis indicated that the signal retained the same cluster and discharge characteristics. Figure 12 illustrates the significant positive correlation observed between directional specificity of discharge and errors made during training.

\section{Discussion}

The LDN was examined for its potential contribution to visual spatial navigation systems in rats. It was found that dorsal LDN neurons code directional information. That is, these cells increased firing when an animal's head was aligned with particular directions in space, irrespective of the animal's location in the environment. The establishment of directional discharge did not appear to be directly related to movement, or to geomagnetic, olfactory, auditory, or kinesthetic sensations. Rather, visual input played an essential role since it was necessary for animals to view the test room before stable directional firing was observed.

Although visual information was initially required to establish directional firing, viewing merely the local visual scene associated with the preferred direction of a cell was not sufficient for the development of stable directional firing. For example, in one experiment, at least $1 \mathrm{~min}$ of room exposure (lights on) was required before reliable directional firing was observed. During this 1 min period, the animal moved about the central platform of the maze such that it could view any particular direction at least twice. Also, results of the context test showed that allowing an animal to view only the scene associated with 
the preferred direction of a cell did not result in maximal firing rates, even when the rat viewed that scene for $5 \mathrm{~min}$. Rather, maximal firing was achieved only after the animal was exposed to additional views of the environment. That LDN directionsensitive cells do not simply respond to a specific pattern of retinal input was also suggested by the finding that firing was unrelated to the animal's location in the environment. These results indicate that while visual input represents an essential component, it is not the only factor that determines LDN directional firing. Rather, LDN directional representations may reflect integration of complex (contextual) multimodal sensory information.

The hypothesis that LDN directional correlates represent integration of visual input with other types of information was further supported by the finding that once directional firing was established, it was maintained for a short period of time (2-3 $\mathrm{min}$ ) in the absence of visual cues. Associations between visual input and other information systems may comprise a neural network that engages computational processes, such as pattern completion (Marr, 1969, 1971), that in turn maintain directional representations despite significantly reduced visual input. Given the extensive reciprocal connections between the LDN and cortex, corticothalamic feedback may importantly contribute to the implementation of such network operations when well-trained animals perform in a familiar environment.

The maintenance of normal LDN directional information without visual input was short-lived when rats performed the maze in darkness. Directional preferences, but not directional specificity, changed after $2-3 \mathrm{~min}$. The specific pattern of change observed (Fig. 10) gave the appearance of a systematic rotation of directional preference in either the cluckwise or counterclockwise direction. Thus, it is postulated that nonvisual systems and/or internal representations of direction (in the form of corticothalamic loops) maintain the specificity with which direction is coded by LDN cells. The distinct contribution of the visual system may be to align, and thereby stabilize, such directional information.

Maintenance of LDN directional representations without visual cues was also relatively short-lived when the rat was confincd to the central platform in darkness. However, if the animal was restricted to the distal end of a maze arm in darkness, directional firing lasted at least $30 \mathrm{~min}$. The comparatively rapid decay during maze performance or when the rat was confined to the round central platform may be related to the fact that during these times, the animals were exposed to a radially symmetric environment that did not provide sufficient nonvisual directional cues. In contrast, the end of a maze arm is asymmetric in shape and a food cup was located only at the distal end. This asymmetric environment may have provided the rat with sufficient nonvisual sensory input that computational circuits maintained the original directional preference.

It might be suggested that the effects of behavioral condition on the duration of directional firing are related to the amount of retroactive interference produced by recently acquired information. Although animals no longer received normal visual input during dark trials, other sensory inputs (e.g., vestibular, kinesthetic, auditory, etc.) continue. It is reasonable to assume that the amount of nonvisual input received as rats traverse the maze is greater than when they remain restricted to an arm end. Therefore, directional representations during maze performance may have changed more quickly because greater interference was produced by the larger amount of current (and perhaps competing) sensory inputs. However, directional firing also changed relatively rapidly when the rat was confined to the central platform of the maze (and not the maze arm). Nevertheless, at least two factors may determine the duration of LDN directional representations: retroactive interference and the extent to which familiar nonvisual spatial cues are available to "stabilize" directional preferences.

The apparently associative properties of the LDN discusscd thus far indicate that the LDN is part of a mnemonic system that is important for accurate spatial navigation. Additional arguments can be made in support of this hypothesis. First, increased numbers of behavioral errors on the maze coincided with less reliable directional firing. This was the case in welltrained animals tested in darkness, and in naive animals that learned the maze for the first tine. In both test situations, good choice accuracy was accompanied by stable and specific directional firing. Second, the results of the context test suggest that contextual knowledge influences the firing rates of LDN cells. Third, at least some properties of directional discharge were plastic, and were shown to be influenced by the behavioral condition of the animals and/or the nature of the visual environment.

If the LDN makes special contributions to the hippocampaldependent spatial navigation system, disruption of LDN function should have significant consequences for hippocampal behaviors and single unit-behavior correlates. Indeed, it was shown recently that reversible inactivation of the LDN not only impairs spatial performance in rats, but also disrupts location-specific discharge by hippocampal cells (Mizumori and Williams, 1992). Furthermore, experimental manipulations that alter LDN spatial representations also alter spatial processing by the hippocampal formation. For example, turning the lights out, or removing the available visual cues, disrupts head directional firing by postsubicular cells (Taube et al,, 1990b), and location-specific discharge by cells in entorhinal cortex (Quirk et al., 1992) and hippocampus proper (O'Keefe and Speakman, 1987; McNaughton et al., 1989; Quirk et al., 1990).

There are relatively few reports on the dynamic nature of spatial information coding by various nuclei within the tectocortical afferent system during active navigation. Direction- and movement-sensitive single-unit activity has been recorded in the nucleus of the optic tract (Hoffmann and Schoppmann, 1975) as well as other midbrain structures of rodents (Rose, 1985). However, these tests involved either anesthetized animals or animals that were not performing spatial memory tasks. Superior collicular activity has only recently been studied in freely moving rats (Weldon and Best, 1992). It was found that the sensory correlates of deep-layer cells varied according to the behavioral condition of the animal. Thus, similar to our findings for LDN cells, deep-layer collicular cell discharge does not merely reflect the immediate sensory environment. Therefore, it is possible that spatial representations at these relatively early stages in the tectocortical pathway are dynamical. Until more is known about the spatial qualities of collicular/pretectal activity, the specific relationship between spatial processing by these structures and the LDN remains to be determined.

LDN efferents project directly to the postsubiculum, presubiculum, parasubiculum, and the entorhinal cortex of the hippocampal formation (Thompson and Robertson, 1987b; van Groen and Wyss, 1990a,b, 1992). There are important differences in the test procedures used by laboratories that have examined single-unit correlates in these hippocampal subregions. 
Nevertheless, one can begin to compare the nature of information representations within these systems. With respect to the postsubiculum, Taube et al. (1990a,b) recently reported that about $25 \%$ of postsubicular units display head direction sensitivity similar to that described above for LDN cells. Other postsubicular cells exhibited movement- or location-related firing. For comparison, over $50 \%$ of dorsal LDN cells showed clear directional firing, and no movement- or location-related cells were observed. Thus, the LDN may be more specialized than the postsubiculum for head directional information.

To the extent that one can compare firing of LDN directional cells in our radial maze spatial learning task and postsubicular directional cells in the cylinder of Taube et al., there appear to be a number of similarities: the specificity of the directional firing, the relative unimportance of spatial location and voluntary movement, and the cells' responses to changes in the visual environment. Both cell types also showed changes in directional preference when animals were placed in different environments. Further, when salient visual cues were removed, both LDN and postsubicular directional cells maintained directional firing although the directional preference changed. The underlying mechanism of the rotational change of directional preference by cells in the two areas may differ since postsubicular cells rotated in only one direction while LDN cells were often observed to change the direction of rotation if a cell was observed for long periods of time. This difference in the rotational properties of directional preferences by LDN and postsubicular cells may reflect regional differences in the nature of the association between visual and nonvisual spatial inputs. Finally, there is at least preliminary evidence that LDN cells, like postsubicular cells, maintain a single reference frame such that when alterations in the visual environment occur, the directional coding of all cells undergo similar changes.

To facilitate future comparisons between LDN and postsubicular function, it will be important to determine the following. (1) The directional properties of postsubicular cells in a spatial memory task in which consideration of direction of movement is essential for accurate performance. This issue is particularly important since it has been reported that such task requirements significantly influence whether hippocampal place fields have a directional component (Bostock et al., 1988; Leonard et al., 1988). (2) It will also be necessary to establish the relationship between the specificity of directional coding in postsubiculum and new spatial learning. (3) The period of time in which the directional cells in postsubiculum remain stable before directional rotation occurs should also be determined. (The present study systematically varied the period of time between lightsoff and the subsequent maze trial, thereby determining that LDN directional representations were stable for at least a few minutes in darkness.)

The specific functional contribution of head direction information in either the LDN or postsubiculum to navigational accuracy remains uncertain. Since the postsubiculum processes information related not only to direction but also to both spatial location and general movement of the rat, the postsubiculum may be involved in more complex, multisensory/motor integration than the LDN. This conclusion, together with the anatomical result that the postsubiculum projects mostly to the ventral LDN (where no head direction cells were found in this study) and not dorsal LDN (where all head direction cells were recorded), suggests that LDN provides the postsubiculum with directional spatial input.
Taube et al. (1990b) suggested that head direction cells might (1) "represent angular relationships among external objects" or (2) "provide information about the azimuth" as animals traverse their environment. The first hypothesis is less likely since directional firing is constant irrespective of retinal image. McNaughton et al. (1991) have elaborated upon the second hypothesis by suggesting that head direction information is derived from the combination of vestibular and hippocampal place inputs. Both Taube et al. and McNaughton et al. suggest that the (postsubicular) head direction information represents the output of hippocampus proper.

We propose that the head direction information in the LDN represents an important visually dependent spatial orientation system input to the hippocampal formation (i.e., the subicular complex and entorhinal cortex). Specifically, the LDN passes on significant directional information that provides spatial constancy despite changes in the retinal image. This spatial constancy function allows animals to have a fixed directional reference frame for use during spatial navigation learning. Such a reference frame may provide animals with a "directional sense" for use in the creation of novel routes to a goal. Thus, as shown by the correlation between choice accuracy on the maze and directional specificity of LDN cells, the more precise the directional reference, the more accurate the performance of the animal. These LDN head direction cells may comprise the fundamental components of this spatial framework much like place cells are thought to represent the fundamental units of a spatial cognitive map in hippocampus (O'Keefe and Nadel, 1978).

In addition to providing the animal with spatial constancy, the LDN may be part of a neural system that subserves directed attention to constellations of salient cues in the animal's visual world. In this context, it is worth noting that the structurally similar thalamic nucleus in primates (Thompson and Robertson, $1987 \mathrm{~b}$ ), the pulvinar, has been shown to play a significant role in visual spatial attention processes (Ungerleider and Christensen, 1979; Petersen et al., 1987). Specifically, Desimone et al. (1990) suggest that the pulvinar may gate extrastriate responses to distracting visual input, thereby focusing one's attention onto a visual target.

The specificity of I.DN directional information is likely to be a product of highly organized, well-defined connections. Given the anatomical data described above, the LDN appears to be positioned to not only transmit directional information to spatially relevant areas of neocortex (e.g., parietal and retrosplenial cortex, cortical regions shown to maintain spatial representations of the animal's environment; Thompson and Robertson, 1987a,b; Chen and McNaughton, 1988; Chandler et al., 1992; McNaughton et al., unpublished observations), but also to receive modulatory feedback. In this way, during extended learning, the neocortex may exert progressively greater influence over LDN output such that more precise, experience-dependent spatial tuning is achieved.

After incorporating LDN afferent information with that from retrosplenial and/or parietal cortex, and subiculum proper, postsubicular efferents encoding direction and/or place are relayed to entorhinal cortex. [Although there are extensive LDN projections to the parasubiculum and presubiculum, their spatial properties are presently unknown. Anatomical evidence, however, indicates that like the postsubiculum, the parasubiculum and the presubiculum are in a position to pass on significant information to the entorhinal cortex (van Groen and Wyss, $1990 \mathrm{a}, \mathrm{b})$.] The entorhinal cortex may in turn integrate spatial 
data from the LDN and/or subicular complex with neocortical afferents, resulting in spatially localized discharge. Specifically, within entorhinal cortex, output of the geniculostriate visual system may provide the hippocampal formation with the necessary detailed information to distinguish visually place A from place $B$ as an animal moves along specified trajectories in space. The entorhinal place information is then passed on to hippocampus proper where location and detailed contextual information are associated, resulting in more precise and dynamical place fields.

It is important to emphasize that our findings suggest that it is not necessary for hippocampus to organize visual information into a visual spatial map (O'Keefe and Nadel, 1978). Rather, the hippocampus may receive preprocessed visual input from LDN that varies according to the direction the animal is facing. The hippocampus may still have cognitive map functions if one defines the map as a composite representation of discrete places in space and the relationships between those places (O'Keefe, 1990). The directional "place fields" of hippocampal cells (O'Keefe and Dostrovsky, 1971; McNaughton et al., 1983a; Mizumori et al., 1989), then, may ultimately represent associations between directional information and the unique sensory/ motor events that define particular places in space (Muller et al., 1991).

In conclusion, the present study provides evidence that a subcortical thalamic structure is involved in a neural system that mediates accurate spatial navigation. This role does not appear to be merely the passive transmission of current sensory information. Rather, the LDN may serve an important integrative function for limbic spatial learning systems.

\section{References}

Andersen RA (1987) Inferior parietal lobule function in spatial perception and visuomotor integration. In: Handbook of physiology: the nervous system, Vol V, Higher functions of the brain (Mountcastle VB, Plum F, Geiger SR, eds), pp 483-518. Bethesda, MD: Waverly.

Barnes CA, McNaughton BL, Mizumori SJY, Leonard BW, Lin L-H (1990) Comparison of spatial and temporal characteristics of neuronal activity in sequential stages of hippocampal processing. Prog Brain Res 83:287-300.

Berthoz A (1990) Reference frames for the pcrception and control of movement. In: Brain and space (Paillard J, ed), pp 81-111. Oxford: Oxford UP.

Bostock EM, Taube JS, Muller RU (1988) The effects of head orientation on the firing of hippocampal place cells. Soc Neurosci Abstr 14:127.

Casagrande VA, Harting JK, Hall WC, Diamond IT (1972) Superior colliculus of the tree shrew: a structural and functional subdivision into superficial and deep layers. Science 177:444-447.

Chandler HC, King V, Corwin JV, Reep RL (1992) Thalamocortical connections of rat posterior parietal cortex. Neurosci Lett 143:237242.

Chen LL, McNaughton BL (1988) Spatially selective discharge of vision and movement modulated posterior parietal neurons in the rat. Soc Neurosci Abstr 14:818.

Dean P (1990) Sensory cortex: visual perceptual functions. In: The cerebral cortex of the rat (Kolb B, Tees RC, eds), pp 275-307. Cambridge, MA: MIT Press.

Desimone R, Wessinger M, Thomas L, Schneider W (1990) Attentional control of visual perception: cortical and subcortical mechanisms. Cold Spring Harbor Symp Quant Biol 55:963-971.

Farah MJ (1988) The neuropsychology of mental imagery. In: Spatial cognition: brain bases and development (Stiles-Davis I, Kritchevsky M, Bellugi U, eds), pp 33-56. Hillsdale, NJ: Erlbaum.

Hoffmann KP, Schoppmann A (1975) Retinal input to direction-selective cells in the nucleus tractus opticus of the cat. Brain Res 99: 359-366.
Ingle DJ (1982) Organization of visuomotor behaviors in vertebrates. In: Analysis of visual behavior (Ingle DJ, Goodale MA, Mansfield RJW, eds), pp 67-109. Cambridge, MA: MIT Press.

Lee KS, Stanford EJ, Cotman C, Lynch G (1977) Ultrastructural evidence for bouton proliferation in the partially deafferented dentate gyrus of the adult rat. Exp Brain Res 29:475-485.

Leonard BJ, McNaughton BL, Barnes CA (1988) Location- and direction-specific discharge of rat hippocampal complex-spike cells in an open field and on the radial 8-arm maze. Soc Neurosci Abstr 14: 396.

Linden R, Perry VH (1983) Massive retinotectal projection in rats. Brain Res 272:145-149.

Marr DA (1969) A theory of cerebellar cortex. J Physiol (Lond) 202: $437-470$.

Marr DA (1971) Simple memory: a theory for archicortex. Philos Trans R Soc Lond [Biol] 262:23-81.

Matthews DA, Cotman C, Lynch G (1976) An electron microscopic study of lcsion-induced synaptogenesis in the dentate gyrus of the adult rat. I. Magnitude and time course of degeneration. Brain Res 115:1-21.

McNaughton BL, Nadel L (1990) Hebb-Marr networks and the neurobiological representation of action in space. In: Neuroscience and connectionist theory (Gluck MA, Rummelhart DE, eds), pp 1-63. Hillsdale, NJ: Erlbaum.

McNaughton BL, Barnes CA, O'Keefe J (1983a) The contributions of position, direction and velocity to single unit activity in the hippocampus of freely-moving rats. Exp Brain Res 52:41-49.

McNaughton BL, O'Keefe J, Barnes CA (1983b) The stereotrode: a new technique for simultaneous isolation of several single units in the central nervous system from multiple unit records. J Neurosci Methods 8:391-397.

McNaughton BL, Leonard B, Chen L (1989) Cortical-hippocampal interactions and cognitive mapping: a hypothesis based on reintegration of the parietal and inferotemporal pathways for visual processing. Psychobiology 17:230-235.

McNaughton BL, Chen LL, Markus EJ (1991) "Dead-reckoning," landmark learning, and the sense of direction: a neurophysiological and computational hypothesis. J Cognit Neurosci 3:190-202.

Meredith MA, Stein BE (1985) Descending efferents from the superior colliculus relay integrated multisensory information. Scicnce 227:657659.

Mizumori SJY, Williams JD (1991) Mnemonic properties of visualsensitive head direction cells in lateral dorsal thalamus. Soc Neurosci Abstr 17:482.

Mizumori SJY, Williams JD (1992) Interdependence of hippocampal and lateral dorsal thalamic representations of space. Soc Neurosci Abstr 18:708.

Mizumori SJY, McNaughton BL, Barnes CA, Fox KB (1989) Preserved spatial coding in hippocampal CAl pyramidal cells during reversible suppression of $\mathrm{CA} 3 \mathrm{C}$ output: evidence for pattern completion in hippocampus. J Neurosci 9:3915-3928.

Mizumori SJY, Perez GM, Alvarado MC, Barnes CA, McNaughton BL (1990) Reversible inactivation of the medial septum differentially affects two forms of learning in rats. Brain Res 528:12-20.

Mizumori SJY, Ward KE, Lavoie AM (1992) Medial septal modulation of entorhinal single unit activity in anesthetized and freely moving rats. Brain Res 570:188-197.

Morrow L, RatcliffG (1988) The neuropsychology of spatial cognition. In: Spatial cognition: brain hases and development (Stiles-Davis J, Kritchevsky M, Bellugi U, eds), pp 5-32. Hillsdale, NJ: Erlbaum.

Muller RU, Kubie JL, Ranck JB Jr (1987) Spatial firing pattern of hippocampal complex-spike cells in a fixed environment. J Neurosci 7:1935-1950.

Muller RU, Kubie JL, Bostock EM, Taube JS, Quirk GJ (1991) Spatial firing correlates of neurons in the hippocampal formation of freely moving rats. In: Brain and space (Paillard J, ed), pp 296-333. New York: Oxford UP.

O'Keefe J (1976) Place units in the hippocampus of the freely-moving rat. Exp Neurol 51:78-109.

O'Keefe J (1990) A computational theory of the hippocampal cognitive map. Prog Brain Res 83:301-312.

O'Keefe J, Dostrovsky J (1971) The hippocampus as a spatial map. Preliminary evidence from unit activity in the freely-moving rat. Brain Res 34:171-175. 
O'Keefe J, Nadel L (1978) The hippocampus as a cognitive map. London: Oxford UP.

O'Keefe J, Speakman A (1987) Single unit activity in the rat hippocampus during a spatial memory task. Exp Brain Res 68:1-27.

Olton DS, Samuelson RJ (1976) Remembrance of places passed: spatial memory in rats. J Exp Psychol [Anim Behav] 2:97-116.

Olton DS, Branch M, Best PJ (1978) Spatial correlates of hippocampal unit activity. Exp Neurol 58:387-409.

Paxinos G, Watson C (1986) The rat brain in stereotaxic coordinates. Sydney: Academic.

Petersen SE, Robinson DL, Morris JD (1987) Contributions of the pulvinar to visual spatial attention. Neuropsychologia 25:97-105.

Quirk GJ, Ranck JB Jr (1986) Firing of single cells in entorhinal cortex is location-specific and phase locked to hippocampal theta rhythm. Soc Neurosci Abstr 12:1524.

Quirk GJ, Muller RU, Kubie JL (1990) The firing of hippocampal place cells in the dark depends on the rat's recent experience. J Neurosci 10:2008-2017.

Quirk GJ, Muller RU, Kubie JL, Ranck JB Jr (1992) The positional firing properties of medial entorhinal neurons: description and comparison with hippocampal place cells. J Neurosci 12:1945-1963.

Ranck JB Jr (1973) Studies on single neurons in dorsal hippocampus formation and septum in unrestrained rats, Pt I, Behavioral correlates and firing repertoires. Exp Neurol 41:461-555.

Ranck JB Jr (1984) Head-direction cells in the deep cell layers of dorsal presubiculum in freely moving rats. Soc Neurosci Abstr 10: 599.

Rolls ET (1990) Functions of neuronal networks in the hippocampus and of backprojections in the cerebral cortex in memory. In: Brain organization and memory (McGaugh JL, Weinberger NM, Lynch G, eds), pp 184-210. New York: Oxford UP.

Rose JD (1985) Dorsal-ventral differences in the midbrain distribution of single neurons with head movement-correlated and locomotioncorrelated firing in the golden hamster. Exp Neurol 87:225-234.

Scfton AJ, Drcher B (1985) Visual system. In: The rat nervous system, Vol 1, Forebrain and midbrain (Paxinos G, ed), pp 169-221. Sydney: Academic.

Sripanidkulchai K, Wyss JM (1986) Thalamic projections to retrosplenial cortex in the rat. J Comp Neurol 254:143-165.

Sparks DL (1989) The neural encoding of the location of targets for saccadic eye movements. J Exp Biol 146:195-207.

Steriade M, Llinas RR (1988) The functional states of the thalamus and the associated neuronal interplay. Physiol Rev 68:649-742.
Steward O, Scoville SA (1976) Cells of origin of entorhinal cortical afferents to the hippocampus and fascia dentata of the rat. J Comp Neurol 169:347-370.

Taube IS, Muller RU, Ranck JB Ir (1990a) Head direction cells recorded from the postsubiculum in freely moving rats. I. Description and quantitative analysis. J Neurosci 10:420-435.

Taube JS, Muller RU, Ranck JB Jr (1990b) Head direction cells recorded from the postsubiculum in freely moving rats. II. Effects of environmental manipulations. J Neurosci 10:436-447.

Thompson SM, Robertson RT (1987a) Organization of subcortical pathways for sensory projections to the limbic cortex. I. Subcortical projections to the medial limbic cortex in the rat. J Comp Neurol 265:175-188.

Thompson SM, Robertson RT (1987b) Organization of subcortical pathways for sensory projections to the limbic cortex. II. Afferent projections to the thalamic lateral dorsal nucleus in the rat. J Comp Neurol 265:189-202.

Ungerleider I.G, Christensen CA (1979) Pulvinar lesions in monkeys produce abnormal eye movements during visual discrimination training. Neuropsychologia 17:493-501.

Vanderwolf C (1969) Hippocampal electrical activity and voluntary movement in the rat. Electroencephalogr Clin Neurophysiol 26:407418.

van Groen T, Wyss JM (1990a) The connections of presubiculum and parasubiculum in the rat. Brain Res 518:227-243.

van Groen T, Wyss JM (1990b) The postsubicular cortex in the rat: characterization of the fourth region of the subicular cortex and its connections. Brain Res 529:165-177.

van Groen T, Wyss JM (1992) Projections from the laterodorsal nucleus of the thalamus to the limbic and visual cortices in the rat. $\mathbf{J}$ Comp Neurol 324:427-448.

Vogt BA, Miller MW (1983) Cortical connections between rat cingulate cortex and visual, motor, and postsubicular cortices. J Comp Neurol 216:192-210.

Vogt BA, Sikes RW, Swadlow HA, Weyand TG (1986) Rabbit cingulate cortex: cytoarchitecture, physiological border with visual cortex, and afferent cortical connections of visual, motor, postsubicular, and intracingulate origin. J Comp Neurol 248:74-94.

Weldon DA, Best PJ (1992) Changes in sensory responsivity in deep layer neurons of the superior colliculus of behaving rats. Behav Brain Res 47:97-101. 